\title{
Influence of Brand Equity Relevance Based on Marketing Du Wei ${ }^{1, a}$ \\ Hainan College of Software Technology, Qionghai City, Hainan Province, 571400 \\ a1258502015@qq.com
}

Keywords: Marketing, brand equity, relevance, structural equation model

\begin{abstract}
Through the model of customer value's effect on brand equity, the thesis constructs marketing strategy, and adopts structural equation model to conduct empirical research. In this model, marketing strategy is the influential factor of brand equity, and value is the intermediary between their effects, that is, marketing strategy has an indirect on brand equity through customer value. It designs the structural elements of relational perspective brand equity, normalizes and develops the research scale of relational perspective brand equity, which provides the theoretical foundation for the measurement study of brand equity.
\end{abstract}

\section{Introduction}

In the past decades, brand marketing has already become the top-level research topic and direction in academic world of marketing, and brand equity is widely regarded to be the important indicator to measure the validity of branding strategy ${ }^{[1,2]}$. Globalization, commercialization of service, enhancement of middle man's influence, accumulation of consumer's experiment and increase of media expense also bring huge challenge to the marketing of tourist destination. As a significant way to differentiate themselves from competitors and gain competitive advantage, brand marketing has been introduced into the marketing of tourist destination. Brand and brand influence have increasingly become the core competitive assets, and tourism destination management has also changed from the traditional brand management era into strategic brand asset management era. However, in recent years, the researches on brand equity all have some shortcomings no matter in the aspects of research contents or industry applicaiton. In the aspect of research contents, it mainly focus on the conception, constitutional dimension and measurement of brand equity, but seldom on the source and incluence factors of brand equity ${ }^{[3]}$; in the aspect of industry application, it mainly focus on the study of fast moving consumer goods industry instead of durable goods industry, which offers new space and entry point to the further development research of brand equity.

According to brand relationship research mode, this thesis speculatively proposes the basic conception of relational perspective brand equity and extracts the structural elements of relational perspective brand equity in terms of the three levels that are cognization, emotion and behavior. And then, the thesis takes the forming process of relational perspective brand equity as the main line, so as to establish the drive relationship model of relational perspective brand equity. At last, it chooses the survey background of mobile phone brand to conduct sample data collection and collation, and data analysis as well as empirical test, so as to come up with some management references in the light of analysis result.

\section{Brand Equity}

The related research on brand equity involves the brand equity's concept, structural dimension, measurement and evaluation model, driving factor as well as its effects and the like. In addition, the research perspective and research method are also not the same. Brand equity is called brand interests as well. At present, the name used within the country is not uniform, even though the adoption of brand equity is more widespread. The scholars also give definitions of brand equity according to different perspectives, which basically from the perspectives of finance, customer and marked at present $^{[4]}$. Base on the customer, there are some classic methods, such as Aaker Model, Keller Model, 
there latitude model as well as the evaluation and measurement model proposed by some domestic scholars.

Brand knowledge is a memory network model, which is composed of node and link. The brand awareness, brand association and brand image all will influence brand equip. therefore, the higher of brand awareness, the more abundant, positive and unique of brand association, and the higher of brand equity. As shown in Figure 1.

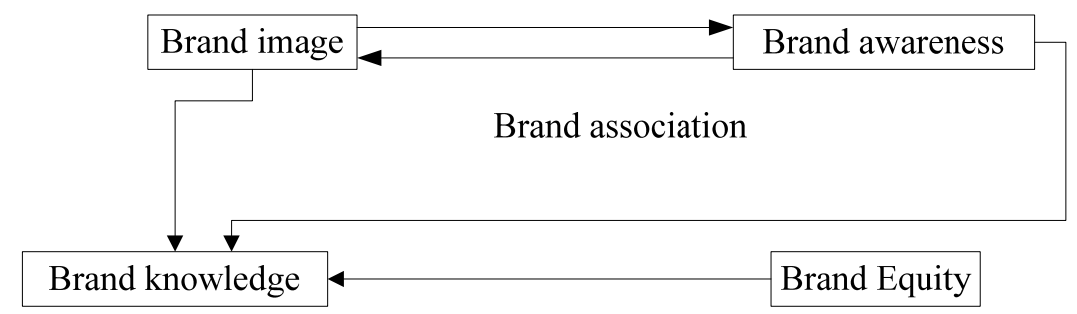

Figure 1. The brand associative network

The five-star model of brand equity, which includes brand awareness, brand association, quality perception, brand loyalty and other proprietary (such as patent, trademark and channel relationship), reflects the view that the enterprise creates a strong brand according to the consumer awareness of the brand. In that model, the five dimensions have coordinate relations without front and back logical order. At the same time, it explains the customer value of each dimension, and rises enterprise value on the basis of customer value. As shown in Figure 2.

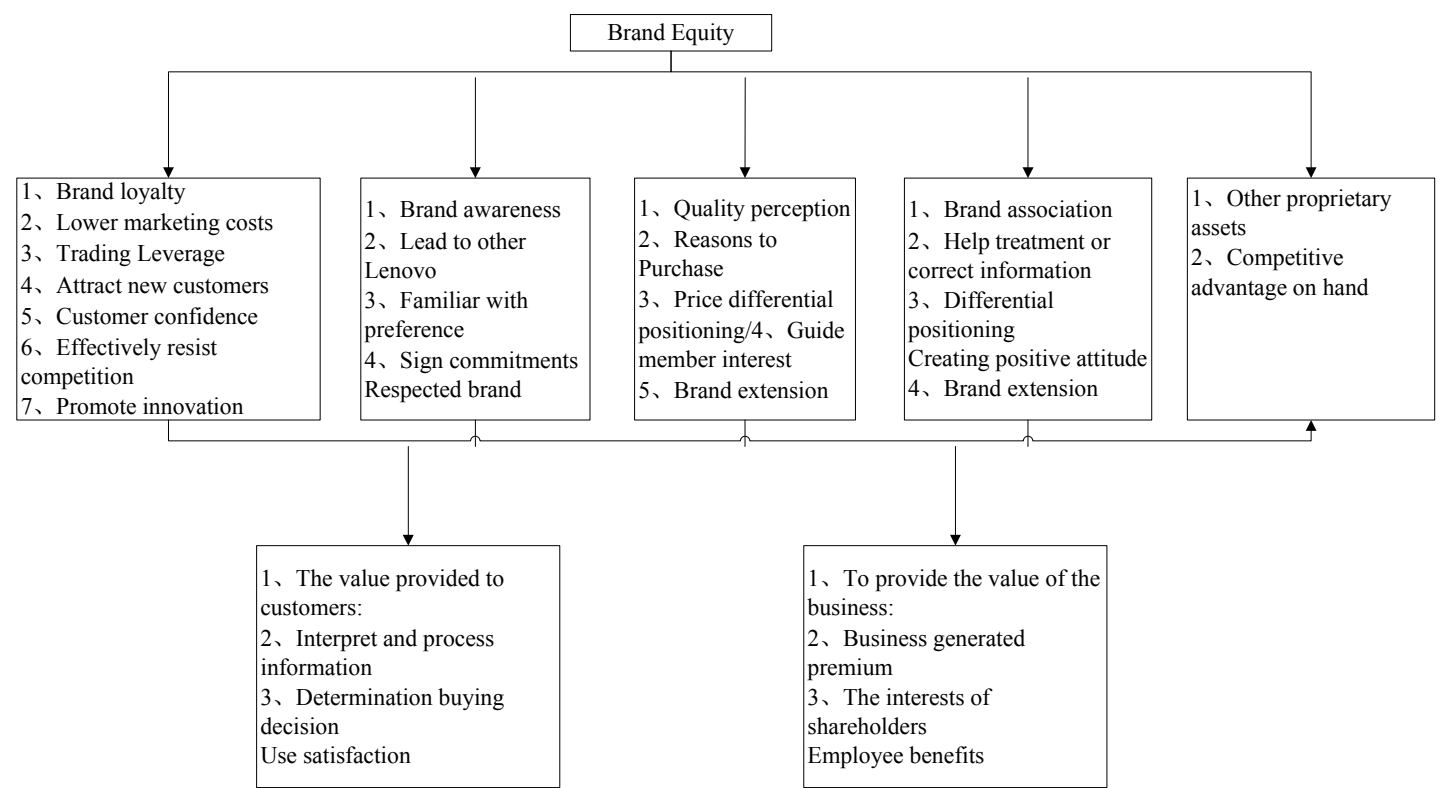

Figure 2. The composition of brand equity

\section{The model and hypothesis of brand equity based on marketing}

The research model reflects the influence relations of marketing strategy and customer value on brand equity as a whole, they jointly constitute the formation process and its different constitute stage of brand equity on the basis of customer perspective. The establishment of this holistic research model basically reflects the logical thinking and the behavior process of the customer purchasing behavior, and the ideas of model establishment is clear. Based on the basic logical relation of customer "before purchase - during purchase - after purchase" ( that is, "strategy contact effect in advance", "customer value perception during the process", "review and evaluation of brand equity later"), the model studies the action mechanism of enterprise marketing activities on brand equity from the perspective of customer. It regards the marketing strategy of the enterprise as the first layer of driver, the perception process of customer on enterprise marketing activities, and the process of customer experience. The benefits and loss brought by this kind of consumption experience form the 
customers' perceived value. The degree of customer's perceived value will further influence the customers' cognition, attitude and behavior after their purchases.

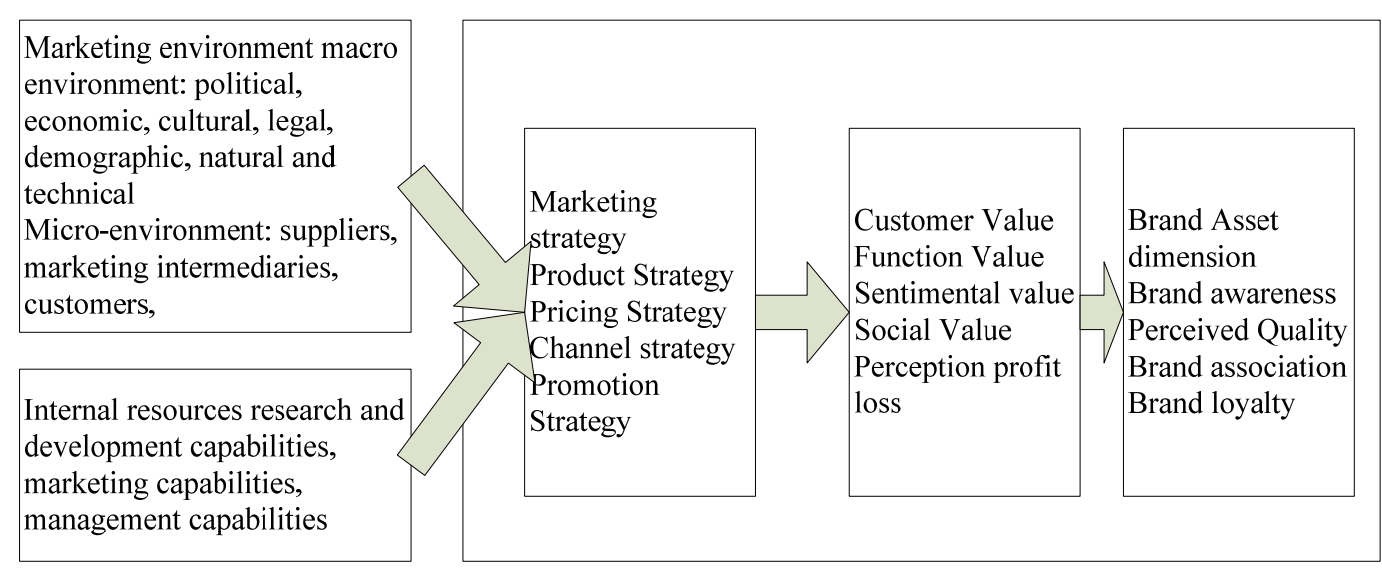

Figure 3. holistic conceptual model of brand equity: predisposing factors, marketing strategy, customer value, $\mathrm{CBBE}$

Under the Chinese local culture background and based on the perspective of customer, Taking the domestic furniture industry as the research object, the thesis analyzes the influence of marketing strategy on brand equity through customer value. According to the relations between product strategy and brand equity, price and brand equity, market image and brand equity, advertising expenditure and brand equity, price promotion and brand equity, this research puts forwards the following research hypothesis:

H1: Style design has a significant positive effect on perceived quality;

$\mathrm{H} 2$ : Product/service quality has a significant positive effect on perceived quality;

H3: Product/service quality has a significant positive effect on brand loyalty;

H4: Price has a significant positive effect on perceived quality;

H5: Market image has a significant positive effect on perceived quality;

H6: Market image has a significant positive effect on brand association;

H7: Advertising expenditure has a significant positive effect on brand awareness;

H8: Advertising expenditure has a significant positive effect on perceived quality;

H9: Advertising expenditure has a significant positive effect on brand association;

H10: Advertising expenditure has a significant positive effect on brand loyalty;

H11: Price promotion has a significant positive effect on brand association;

H12: Price promotion has a significant positive effect on brand loyalty;

H13: Style design has a significant positive effect on function value;

H14: Service/product quality has a significant positive effect on function value;

H15: Price has a significant positive effect on perceived cost.

\section{An empirical research of brand equity relation based on marketing strategy}

\section{Design of research method}

In order to verify the drive relation of brand equity elements under the relational perspective, this research adopts the test method used in the study of variable path relationship. Structural Equation Model (SEM) is a general and important linear statistical modeling techniques. It will use AMOS 17.0 statistical software to conduct SEM analysis. Through sampling survey, it collects and sort out 185 sample data. By exploratory factor analysis, it removes the low load and cross load items, reserves 34 items, and extracts 7 common factors among them, which correspond to 7 component elements of brand equity with the perspective of relations; through the analysis of the validation factors, it conducts a more in-depth analysis of the first order and second order factors subordinate 
problem of 34 items. The final result shows that the residual 34 items can be used to measure the 7 factor variables of relational perspective brand equity, and then sort them out into 3 structural levels, which has good reliability and validity.

SEM is a kind of cause-and -effect relation model, which consists of latent variable and observational variable. It can be divided into two parts, which are measurement model and structural model. The measurement model is used to describe the relation between observational variable and latent variable; and the structural model is used to describe the relation among latent variables. The matrix equations of the two parts of SEM are shown as follow:

1) Measurement model:

$$
\begin{aligned}
& x=\wedge_{x} \xi+\delta \\
& y=\wedge_{y} \eta+\varepsilon
\end{aligned}
$$

$\mathrm{X}$ refers to the vector of exogenous indicators; $\mathrm{y}$ refers to the vector endogenous indicators; $\wedge_{x}$ refers to the relationship between exogenous indicator and exogenous latent variables, which means the factor load matrix of the exogenous indicators on the exogenous latent variables; $\wedge_{y}$ refers to the relationship between exogenous variables and endogenous latent variables, which means the factor load matrix of the endogenous indicators on the endogenous latent variables.

2) Structural model:

For the relation among the latent variables, the structural equation is usually written as follows:

$$
\eta=B \eta+\gamma \xi+\zeta
$$

Where, $\eta$ refers to endogenous latent variable; $\xi$ refers to exogenous latent variable; B refers to the relations among endogenous latent variable; $\Gamma$ refers to the influence of exogenous latent variable on endogenous latent variable; and $\zeta$ refers to the residuals of structural equation, which reflects the parts that fail to be explained in the equation.

\section{Analysis of reliability and validity of measurement variables}

In this research,there are a total of 450 questionnaires returned, among which the number of effective ones is 372 , and the effective recovery rate is $83 \%$. It will make basic statistical analysis on this sample. The data analysis will use statistical analysis software SPSS 21.0, which will deal with the research data. Through descriptive statistical analysis, it observes the distribution of each data, and then test the degree of consistency among various indicators through the reliability analysis, test the validity of each item on the variables through validity analysis, and finally, adopts correlation analysis and regression analysis to conduct the model hypothesis testing. This thesis adopts the most commonly used Cronbach-a^iha coefficient to show the confidence level. The reliability coefficient criterion is shown in Table 1.

Table 1. Reliability coefficient criterion

\begin{tabular}{ccc}
\hline & $\begin{array}{c}\text { Questionnaire reliability } \\
\text { coefficient }\end{array}$ & $\begin{array}{c}\text { Univariate reliability } \\
\text { coefficient }\end{array}$ \\
\hline $\mathrm{a}$ & 0.7 & 0.5 \\
\hline
\end{tabular}

That is, if the Cronbach- $\mathrm{a}^{\wedge}$ iha coefficient of the whole scale is above 0.7 , and the Cronbach-a ${ }^{\wedge}$ iha coefficient of each variable is above 0.5 , it indicates taht the reliability of the scale is good, and it can be further analyzed.

In this research,through calculation, it finds the composite reliability (CR) of each research variable is above 0.8 , which is above critical value 0.5 . Therefore, the result of this questionnaire is considered to be credible. It indicates that the measuring scale has high internal consistency in this research, all of which can reach the level of credibility. 
Table 2. Reliability analysis result of official research

\begin{tabular}{cccc}
\hline Research Reliability & $\begin{array}{c}\text { Term Number of } \\
\text { measurement problem }\end{array}$ & Cronbach'a & $\begin{array}{c}\text { Composite } \\
\text { Reliability(CR) }\end{array}$ \\
\hline Style design & 5 & 0.881 & 0.881 \\
Product/service quality & 6 & 0.880 & 0.883 \\
Product price & 3 & 0.805 & 0.822 \\
Advertising expenditure & 3 & 0.898 & 0.898 \\
Price promotion & 3 & 0.847 & 0.852 \\
Function value & 5 & 0.891 & 0.893 \\
Setimental value & 5 & 0.924 & 0.93 \\
Social value & 4 & 0.934 & 0.935 \\
Perceived Benefit & 6 & 0.903 & 0.904 \\
Brand awareness & 4 & 0.852 & 0.854 \\
Perceived quality & 5 & 0.925 & 0.925 \\
Brand association & 7 & 0.911 & 0.914 \\
Brand loyalty & 6 & 0.927 & 0.929 \\
Total brand brand equity & 4 & 0.909 & 0.943 \\
\hline
\end{tabular}

It conducts the confirmatory factor analysis through bringing all the sub-dimensionalities like marketing strategy, customer value, brand equity into an overall measurement model (consists of 62 measurement items). The result shows that the standard load coefficients for each observation variable on the corresponding latent variable are all above 0.5 , which locates between 0.56 to 0.92 . The $\mathrm{t}$ value of its factor loading is from 12.16 to 21.67, which all pass the $\mathrm{t}$ test and show the significance on the level of $p<0.001$. At the same time, all the Average Variance Extracted (AVE) are above 0.5 . AVE is to calculate the average variance explanatory power of the measurement items on the corresponding variables. The higher of AVE, the higher the reliability of the variable is. Its discriminant criteria is that AVE is above 0.5. In this research, the AVE values of all the latent variables are above 0.5. Therefore, this study has high convergent validity for latent variable measurements. In this study, only the correlation codfficients of BRL and BRS are 0.86, which is above 0.85 , and all of the others are below 0.85 . The vast majority of the square root of Average Variance Extracted (AVE) is larger than the correlation coefficient between this factor and other factors (except PVC an FUV, PVQ and BRA, BRS and BRA,BRL). Therefore, it shows that each dimension has discriminant validity.

This research adopts 7 indicators to evaluate and study the overall goodness of fit for the model, which are $2 / \mathrm{df}, \mathrm{RMSEA}, \mathrm{GFI}, \mathrm{CFI}, \mathrm{NFI}, \mathrm{NNFI}$ and SRMR. As shown in Chart 2, it is considered that the fitting between the data and theoretical measurement model is well. Through the analysis of LISREL measurement model, it finds that the corresponding T values of the $62 \lambda \mathrm{i}$ values are all more than 2.00, which means these 62 parameters all reach the statistically significant level.

Table 3. Test of goodness for fit of measurement model

\begin{tabular}{clllllll}
\hline & $\chi 2 / \mathrm{df}$ & RMSEA & GFI & CFI & NFI & NNFI & SRMR \\
\hline $\begin{array}{c}\text { Evaluation } \\
\text { criterion }\end{array}$ & $<3$ & $<0.08$ & $>0.9$ & $>0.9$ & $>0.9$ & $>0.9$ & $<0.08$ \\
$\begin{array}{c}\text { Constitutive } \\
\text { model }\end{array}$ & 2.559 & 0.069 & 0.70 & 0.98 & 0.95 & 0.97 & 0.066 \\
\hline
\end{tabular}

The results of model validation factor analysis show that the dimensional defination between customer value and brand equity are empirical supported in this study, that is, customer value is composed of four dimensions, which are function value, sentimental value, social value and perceived cost; brand equity is also composed of four dimesions, which are brand awareness, perceived quality, brand association and brand loyalty.

This thesis takes style design, product/service quality, price, advertising expenditure and price promotion as the exogenous latent variables, and takes function value, sentimental value, social value, perceived cost, brand awareness, perceived quality, brand association and brand loyalty as endogenous latent variables, and it is considered that the fitting between the data and theoretical 
measurement model is well. Through the analysis of LISREL measurement model, it finds that the corresponding $\mathrm{T}$ values of the $62 \lambda \mathrm{i}$ values are all more than 2.00 , which means these 62 parameters all reach the statistically significant level.

Table 4. Test of goodness for fit of structural equation model

\begin{tabular}{clllllll}
\hline & $\chi 2 / \mathrm{df}$ & RMSEA & GFI & CFI & NFI & NNFI & SRMR \\
\hline $\begin{array}{c}\text { Evaluation } \\
\text { criterion }\end{array}$ & $<3$ & $<0.08$ & $>0.9$ & $>0.9$ & $>0.9$ & $>0.9$ & $<0.08$ \\
$\begin{array}{c}\text { Constitutive } \\
\text { model }\end{array}$ & 3.225 & 0.084 & 0.64 & 0.97 & 0.95 & 0.96 & 0.085 \\
\hline
\end{tabular}

When calculating effect, according to the hypothesis conclusion mentioned above, it doesn't calculate the effects between price and perceived quality, advertising expenditure and brand loyalty. As shown in Chart 5.

Table 5. Relationship among variables and the test of significance

\begin{tabular}{ccccc}
\hline Hypothesis & $\begin{array}{c}\text { Hypothesial path } \\
\text { relationship }\end{array}$ & $\begin{array}{c}\text { Standardization path } \\
\text { coefficient }\end{array}$ & T Value & Conclusion \\
\hline H1 & STY $\rightarrow$ PVQ & 0.05 & 0.65 & Nonsupport \\
H2 & QUA $\rightarrow$ PVQ & 0.18 & 2.52 & Support \\
H3 & QUA $\rightarrow$ BRL & 0.04 & 1.04 & Nonsupport \\
H7 & ADV $\rightarrow$ BRS & 0.01 & 0.14 & Nonsupport \\
H8 & ADV $\rightarrow$ BRL & 0.04 & 0.60 & Nonsupport \\
H9 & PRM $\rightarrow$ BRS & 0.12 & 2.30 & Opposite conclusion \\
H11 & STY $\rightarrow$ FUV & 0.42 & 5.18 & Support \\
H12 & QUA $\rightarrow$ FUV & 0.39 & 4.89 & Support \\
H13 & PRI $\rightarrow$ PVC & 0.33 & 5.41 & Support \\
H14 & ADV $\rightarrow$ AFV & 0.51 & 9.03 & Support \\
H15 & ADV $\rightarrow$ SOV & 0.39 & 5.47 & Support \\
\hline
\end{tabular}

By synthesizing the direct action model of marketing strategy on brand equity, and the indirect action model of marketing strategy on brand equity, this thesis believes that only hypothesis 4, 5, 6 and 10 are not supported among the 27 hypothesis. According to LISREL 8.7 procedure, it gets the result of path relationship. This research further draws the structural equation model supported by the data. As shown in 5.2.

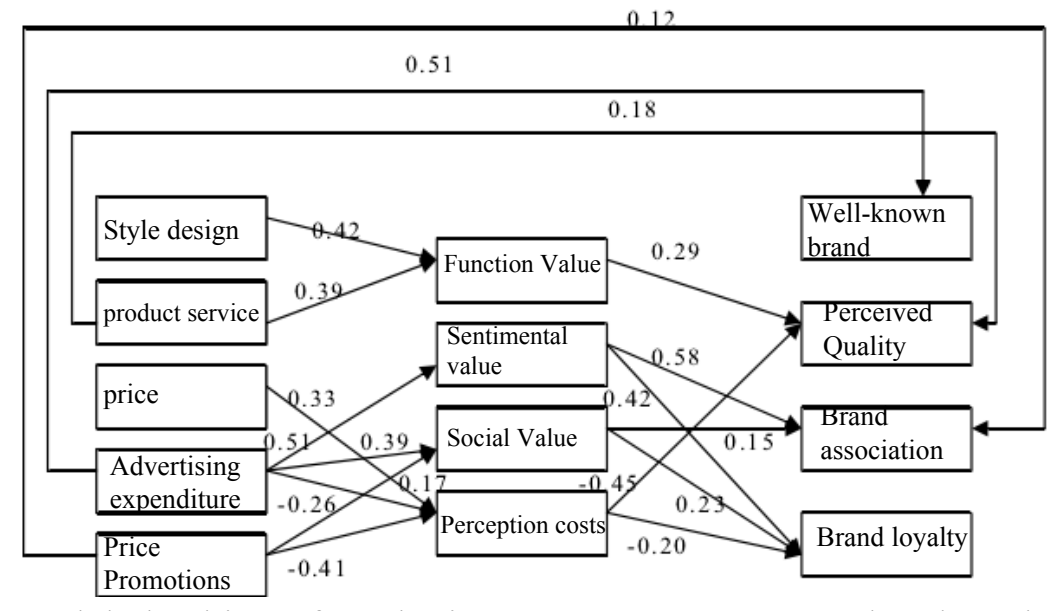

Figure 4. Path model checking of marketing strategy, customer value, brand equity function

\section{Conclusion and analysis}

From the results of the empirical research, style design and product/service quality has a significant positive effect on perceived quality through function value. Function value plays an intermediary role among style design, product/service quality and perceived quality. The former one is complete intermediary effect $(0.12)$, and the latter one is sectional intermediary effect $(0.11)$. Therefore, when the consumers conduct purchasing, style design and product/service quality both 
play an important role in making decisions, and function value plays an intermediary role. Product/service quality has a significant effect on its direct influence on brand loyalty (0.48), and there is no intermediary variable. It is thus clear that product/service quality is the most direct influence factors of customers' brand loyalty. Therefore, the enterprises must pay enough attention to product/service quality, and comprehensively improve the quality of products and services. At the same time, they should focus on the style design, which contributes to improve the function value of the furniture, so as to meet consumers' demand.

From the the results of the empirical research, price has a non-significant influential effect on perceived quality, and the hypothesis doesn't gain any support. However, in the previous empirical studies, price has a significant positive effect on perceived quality. In this analysis, the reason of getting the different conclusion may have a great relationship with China's market environment. Advertising expenditure has a significant positive effect on brand awareness, which is a direct influence, and there is no intermediary variable. It indicates that advertisement plays a pivotal role in shaping the brand awareness. The customers learn about the product brand through advertisements and have perception on the products through media advertising and intensity of advertising. Therefore, the more intensive of advertising is, the more expenditure the advertising pays, and the higher brand awareness gets, so as to establish the strong brand equity. When the advertising expenditure reduces, the brand awareness of the customers will decrease as well. meanwhile, advertising is an important way to develop, form and manage the brand image.

The empirical result shows that the direct effect value of price promotion on brand association is 0.12 , the indirect effect value through social value is 0.003 , and the total effect value is 0.015 . These indicate that price promotion has a significant positive effect on brand association, where social value is regarded to be a sectional intermediary variable with less effect. It is contrary to the original hypothesis. Price promotion indirectly affects brand loyalty through social value and perceived cost, and its intermediary effect are 0.04 and 0.05 respectively. Social value and perceived cost are sectional intermediary, whose effect is less, which is contrary to the original hypothesis.

\section{References}

[1] Fan Zhigang, Wu Xiaobo. Understanding and Thought of Co-branding Strategy in the Enterprise. Business Studies, Vol 04, 2009,p 21-24.

[2] Wang Xiaoyu. Overview of Effects Research on Brand Equity in Negative Marketing Events. Foreign Economics and Management, Vol 2, 2010, p 54-57.

[3] Gao Yongqiang. Stragtegy Analysis of Career related Marketing in Chinese Enterprise. Contemporary Economic Management, Vol 4, 2007, p 87-88.

[4] Wen Bin, Wang Xia. Research on Decision and Evaluation Index System of Co-branding. Philosophy and Social Science of Guangxi University Journal, Vol 4, 2009, p 266-268.

[5] Fan Gongguang, Wufang. Research on Adjustment Factors of Co-branding Matching and Co-branding Matching Effect Relationship. Techological Economy, Vol 10, 2008, p 108-114.

[6] Bian Yaying, Wu Fang. Consumer Evaluation and its Influence Factors of Co-branding: An Empirical Analysis Based on Two-dimensional Structure. Management World. Vol 10, 2009, p 115-125.

[7] Wang Haizhong, etc. Relationship between Consumer Mode of Brand Equity and Output Mode of Product Marketing. Management World, Vol1, 2006, p 106-119.

[8] Liang Sen, Nie Yue, Lv Tao. An Empirical Study of Perceived Quality's effects on Brand Loyalty. Journal of Marketing Science, Vol (34), 2007, p 86-97.

[9] Zhuang Guijun, Zhou Youlinn. Dynamic Combination Model of Relationship Marketing. Journal of Beijing Technology and Business University, Vol (1), 2007, p 22-26. 